\title{
Neural Substrates Underlying the Passive Observation and Active Control of Translational Egomotion
}

\author{
Ruey-Song Huang, ${ }^{1}$ Ching-fu Chen, ${ }^{2}$ and $\odot$ Martin I. Sereno ${ }^{3,4}$ \\ ${ }^{1}$ Institute for Neural Computation and ${ }^{2}$ Department of Electrical and Computer Engineering, University of California, San Diego, La Jolla, California 92093, \\ ${ }^{3}$ Cognitive, Perceptual, and Brain Sciences, University College London, London WC1E 7HX, United Kingdom, and ${ }^{4}$ Department of Psychological Sciences, \\ Birkbeck-UCL Centre for NeuroImaging, Birkbeck College, University of London, London WC1H 0AP, United Kingdom
}

\begin{abstract}
Moving or static obstacles often get in the way while walking in daily life. Avoiding obstacles involves both perceptual processing of motion information and controlling appropriate defensive movements. Several higher-level motion areas, including the ventral intraparietal area (VIP), medial superior temporal area, parieto-insular vestibular cortex (PIVC), areas V6 and V6A, and cingulate sulcus visual area, have been identified in humans by passive viewing of optic flow patterns that simulate egomotion and object motion. However, the roles of these areas in the active control of egomotion in the real world remain unclear. Here, we used functional magnetic resonance imaging (fMRI) to map the neural substrates underlying the passive observation and active control of translational egomotion in humans. A wide-field virtual reality environment simulated a daily scenario where doors randomly swing outward while walking in a hallway. The stimuli of door-dodging events were essentially the same in two event-related fMRI experiments, which compared passive and active dodges in response to swinging doors. Passive dodges were controlled by a computer program, while active dodges were controlled by the subject. Passive dodges activated several higher-level areas distributed across three dorsal motion streams in the temporal, parietal, and cingulate cortex. Active dodges most strongly activated the temporal-vestibular stream, with peak activation located in the right PIVC. Other higher-level motion areas including VIP showed weaker to no activation in active dodges. These results suggest that PIVC plays an active role in sensing and guiding translational egomotion that moves an observer aside from impending obstacles.
\end{abstract}

Key words: avoidance; dodge; dorsal motion streams; self-motion; vestibular cortex

\section{Introduction}

Obstacles are present everywhere when we navigate through natural and human-made environments. Avoiding obstacles during walking is critical to preventing bodily injury (Catena et al., 2009). Obstacle avoidance involves the following sequence of perceptual, cognitive, and motor processes: (1) detecting an impending object; (2) determining the collision course in the body part-centered reference frames (i.e., where it might hit on the observer); and (3) planning and executing appropriate avoidance movements (Graziano and Cooke, 2006; Pearson and Gramlich, 2010). Optic flow is one of the essential cues for guiding egomotion among stationary or moving objects (Marigold, 2008; Bremmer, 2011). Monkey neurophysiology and human neuroimaging studies have demonstrated that passive viewing of optic flow stimuli activates several higher-level motion areas, including the medial superior temporal area (MST; Duffy, 1998), ventral intraparietal area (VIP) (Duhamel et al., 1998; Bremmer et al., 2001; Sereno and Huang, 2006), parieto-insular ves-

\footnotetext{
Received June 29, 2014; revised Dec. 31, 2014; accepted Feb. 4, 2015.

Author contributions: R.-S.H., C.-f.C., and M.I.S. designed research; R.-S.H. and C.-f.C. performed research;

R.-S.H., C.-f.C., and M.I.S. analyzed data; R.-S.H., C.-f.C., and M.I.S. wrote the paper.

This work was supported by National Institutes of Health Grant R01-MH-081990 to M.I.S. and R.-S.H., and a Royal Society Wolfson Research Merit Award to M.I.S.

The authors declare no competing financial interests.

Correspondence should be addressed to Ruey-Song Huang, Institute for Neural Computation, University of California, San Diego, La Jolla, CA 92093. E-mail: rhuang@ucsd.edu.

DOI:10.1523/JNEUROSCI.2647-14.2015

Copyright $\odot 2015$ the authors $\quad 0270-6474 / 15 / 354258-10 \$ 15.00 / 0$
}

tibular cortex (PIVC; Cardin and Smith, 2010), area V6 (Pitzalis et al., 2006, 2010), and cingulate sulcus visual area (CSv; Wall and Smith, 2008). Moving random dots are often used to generate simple optic flow patterns (Pitzalis et al., 2013a), but they are unnatural for simulating complex scenes comprising object motion and egomotion.

Recent neuroimaging studies have begun to use virtual reality (VR) simulation to investigate the neural substrates of egomotion with or without the presence of obstacles (Field et al., 2007; Billington et al., 2010, 2013). Two-dimensional VR scenes rendered with near-realistic textures provide sufficient cues to the spatial layout of the local environment (e.g., path boundaries and object locations). Furthermore, observers can passively view preprogrammed scenes or actively navigate in an interactive VR environment (Hartley et al., 2003). A recent study revealed the neural substrates of passive heading detection and active steering through ground obstacles (Billington et al., 2013). To date, few studies have used VR to study active avoidance of impending obstacles that intrude into an observer's personal space during simulated egomotion (Calabro and Vaina, 2012). One of the obstacle avoidance scenarios in daily life is to move aside from a swinging door during walking, which involves motion detection and translational (lateral) egomotion of the body. While the aforementioned motion areas are involved in the perceptual processing of optic flow, their roles in the active control of translational egomotion remain unclear. 


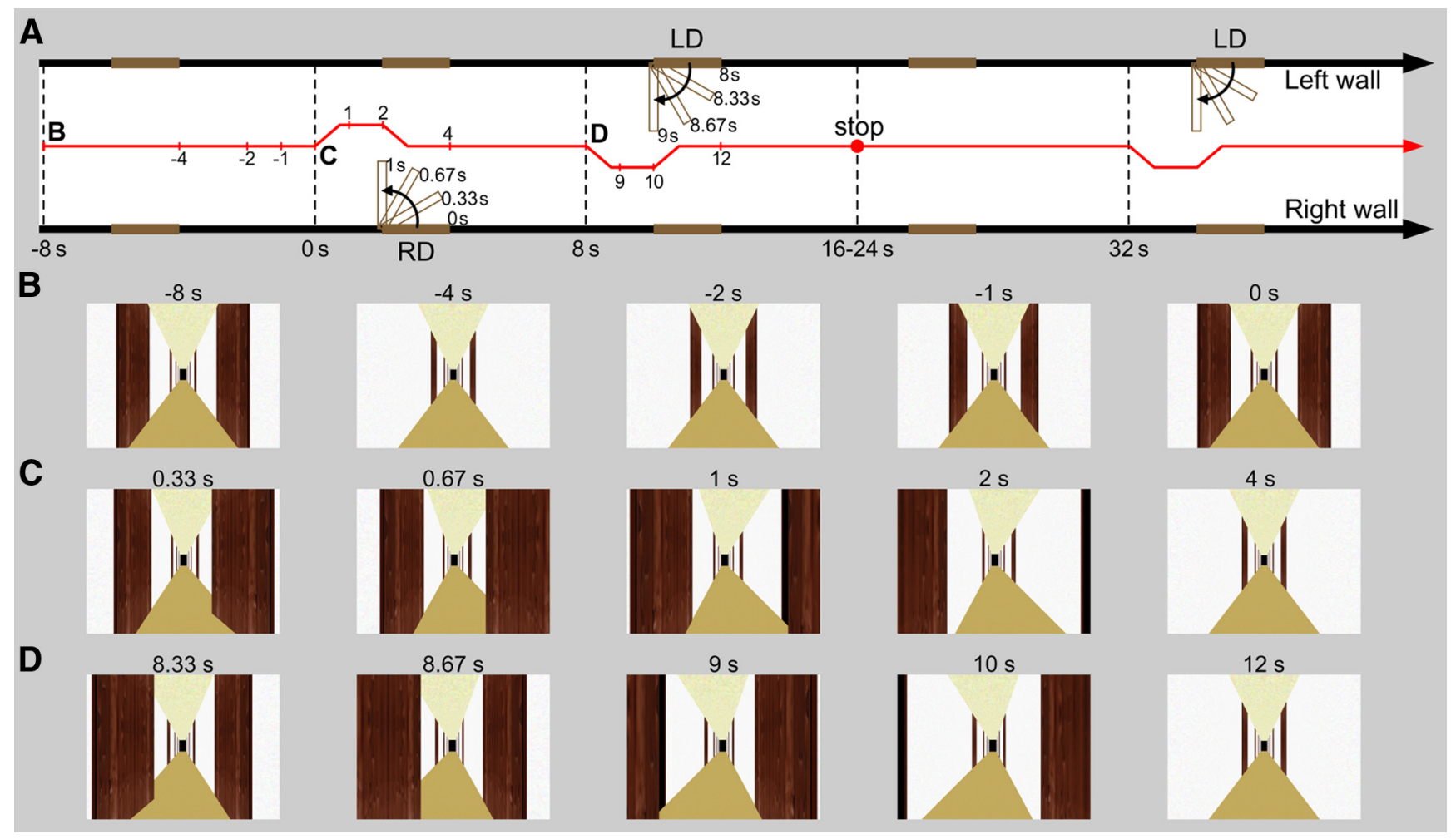

Figure 1. Experimental design and stimuli. $A, A$ bird's eye view of a preprogrammed egomotion trajectory (red trace) in a virtual hallway (schematics not drawn to scale). The timeline starts at $-8 \mathrm{~s}$ for illustration purposes here. Each vertical dashed line indicates the starting point of a virtual block (B, C, and D indicate what is shown in panels B, C, and D). The red spot indicates a stopping period during $16-24 \mathrm{~s}$, where the scene is identical to those at $-8,0$, and $8 \mathrm{~s}$. $\boldsymbol{B}$, Key frames during straight walking with doors closed. C, Key frames during and after an RD event starting at 0 s. $\boldsymbol{D}$, Key frames during and after an LD event starting at $8 \mathrm{~s}$. In each LR or RD event, a door swings open to $90^{\circ}$ in $1 \mathrm{~s}$ and blocks $40 \%$ of the width of the hallway.

We used functional magnetic resonance imaging (fMRI) to investigate the neural substrates underlying the passive observation and active control of translational egomotion (dodging swinging doors) in a VR environment. In two event-related fMRI experiments, we compared activation maps driven by passive and active dodges. Subjects viewed essentially the same stimuli in both experiments but briefly took control in active dodges. We hypothesized that passive observation of dodges would activate areas MST, VIP, V6, CSv, and PIVC, which respond to egomotion-compatible stimuli; and that PIVC would be heavily involved in active dodges because of its role in processing visual-vestibular information during head and body motion.

Preliminary results were published in abstract form at the 2013 Annual Meeting of the Society for Neuroscience.

\section{Materials and Methods}

\section{Participants}

Ten healthy right-handed participants ( 9 females; age range, $19-23$ years; mean age, 20.8 years) with normal or corrected-to-normal vision participated in this study. All participants gave informed consent according to protocols approved by the Human Research Protections Program at the University of California, San Diego (UCSD).

\section{Simulated egomotion in the MRI scanner}

A VR environment was programmed (by R.-S.H. and C.-f.C.) in C programming language and Open GL Performer library to generate realtime animations of walking down a virtual hallway (Fig. 1). The hallway was constructed by concatenating endless virtual blocks of the same length, with a room (door) on either side of each block. The visible range of the hallway was limited to five virtual blocks ahead of the observer's current position. The ceiling, walls, and floor were rendered in soft textures generated by Gaussian noise. Simulated forward egomotion in the hallway was set at a constant speed of $8 \mathrm{~s}$ per virtual block (i.e., the observer passed a pair of opposite facing doors every $8 \mathrm{~s}$ ). The animation occasionally froze at the starting point of a virtual block for $8 \mathrm{~s}$ and then resumed moving (Fig. 1A, "stop"; see Experiment 1), which simulated a transition between stopping and walking (Fig. 2). The VR scenes were rendered in $1024 \times 768$ pixels at 60 frames/s by a custom-built portable computer running the Linux operating system. The VR stimuli were back-projected from the MRI console room through a wave-guide onto a custom-built semicircular screen inside the scanner bore using a video projector (model 3300MP, Dell Inc.) whose standard lens had been replaced with a 7.38-12.3 foot focal length XtraBright zoom lens (Buhl Optical). Subjects lay supine on the scanner table with their heads propped up by foam padding in the head coil. This setup allowed the subject to tilt the head forward $\left(\sim 30^{\circ}\right)$ and directly view the stimuli on a $38 \times 23 \mathrm{~cm}$ region on the semicircular screen $\sim 22 \mathrm{~cm}$ from their eyes without a mirror, which resulted in an approximate field of view (FOV) of $82^{\circ} \times 55^{\circ}$. Additional foam padding was used to immobilize the head in the head coil. Subjects were instructed to keep their heads still while maintaining central fixation at the distant end of the hallway (as indicated by a darkened region) throughout all functional scans. Before fMRI experiments, subjects were trained for $\sim 20$ min using exactly the same stimuli in a custom-built MRI simulator to ensure task compliance and minimize head movements.

\section{Experimental design}

Two event-related fMRI experiments were designed to map the neural substrates underlying the passive observation and active control of translational egomotion. Two $384 \mathrm{~s}$ scans were acquired for each experiment in the same functional session. In Experiment 1 , subjects passively viewed preprogrammed scenes of avoidance of swinging doors during simulated walking down the hallway (Fig. 1). The goal of Experiment 1 was to establish a basemap of cortical regions activated by passive perception of forward and translational egomotion. In Experiment 2, subjects actively dodged the swinging doors during simulated walking in a manner similar to playing a first person-perspective video game. The goals of Experiment 


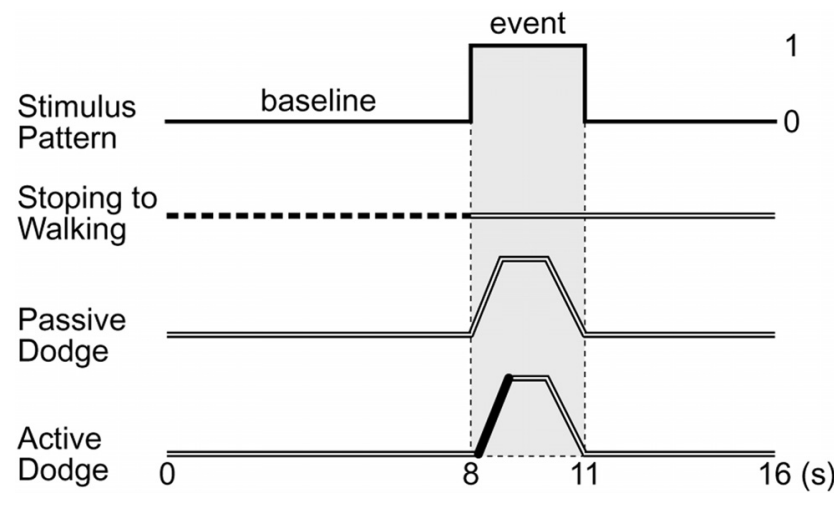

Figure 2. Event-related designs. The stimulus pattern models a 3 s onset (shaded region) for all event types. The dashed line indicates a period of stopping. Double lines indicate egomotion trajectories controlled by the computer. The thick black segment indicates a brief period of active control by the subject.

2 were to determine whether active dodges recruit the same or different sets of cortical regions activated in Experiment 1 and to investigate the temporal dynamics in these regions during active dodges. Passive observation of dodges was not mixed with active dodges in the same experiment because subjects then would have been burdened with a random additional decision of whether to respond or not (i.e., a go vs no-go task), which rarely happens in real-life situations.

Experiment 1: passive observation of forward and translational egomotion. In each $384 \mathrm{~s}$ scan, subjects passively viewed three types of events, stopping to walking (S2W), the left door (LD) swung open, and the right door (RD) swung open, with each occurring 12 times in a pseudorandom order. The same event did not repeat more than three times in a row. An S2W event was defined as the transition between $8 \mathrm{~s}$ of stopping and $8 \mathrm{~s}$ of straight walking (forward egomotion) with doors closed (Figs. $1,2)$. The average interval between two successive S2W events was $30.3 \pm$ $13.6 \mathrm{~s}$. In passive-dodge events, either the LD or RD started to swing into the hallway when the observer entered the starting point of a virtual block (Fig. $1 A$, vertical dashed line). The door swung at a moderate speed (from $0^{\circ}$ to $90^{\circ}$ in $1 \mathrm{~s}$ ) so as to prompt a dodge without inducing a strong sense of imminent collision (Billington et al., 2011). All passive dodges occurred during continuous forward egomotion and were not preceded by periods of stopping (Fig. 2). The average interval between two successive $\mathrm{LD}$ events was $32.7 \pm 26.7 \mathrm{~s} ; 34.2 \pm 22 \mathrm{~s}$ for RD events. At the beginning of each LD or RD event, the door swung open and the view of the virtual camera started to pan toward the opposite direction (Fig. 1A, observer's trajectory), which generated a sense of translational (lateral) egomotion in addition to forward egomotion (Fig. 1C,D). At $0.75 \mathrm{~s}$ in each event, the camera reached the maximum lateral displacement at $15 \%$ of the width of the hallway. Forward egomotion was continued at that position until the observer passed the door at $2 \mathrm{~s}$. The camera's view then automatically returned to the hallway center, which also resulted in a sense of forward and translational egomotion. All subjects reported that they were vigilant and attentive to the stimuli during the experiment.

Experiment 2: active control of translational egomotion. In each $384 \mathrm{~s}$ scan, subjects viewed a computer simulation of continuous walking without stopping in the hallway. At the starting point of each virtual block, there were three possibilities with equal probability, as follows: (1) the left door swung open (LD event); (2) the right door swung open (RD event); and (3) both doors remained closed. The same event did not repeat more than three times in a row. The interval between two successive $\mathrm{LD}$ events was $24.8 \pm 14.7 \mathrm{~s} ; 22.4 \pm 12.4 \mathrm{~s}$ for RD events. Subjects were not informed of either the experimental hypothesis or event probability, which introduced uncertainty in performing the task. Subjects were required to actively dodge each swinging door by holding down a button (on a two-button response pad) in the opposite direction until a subjective margin of safety was reached (Figs. 2, 3). The computer program then immediately resumed control and maintained a brief moment of forward egomotion at the maximum lateral position, where the button was released; subsequently, the view of the camera was programmed to
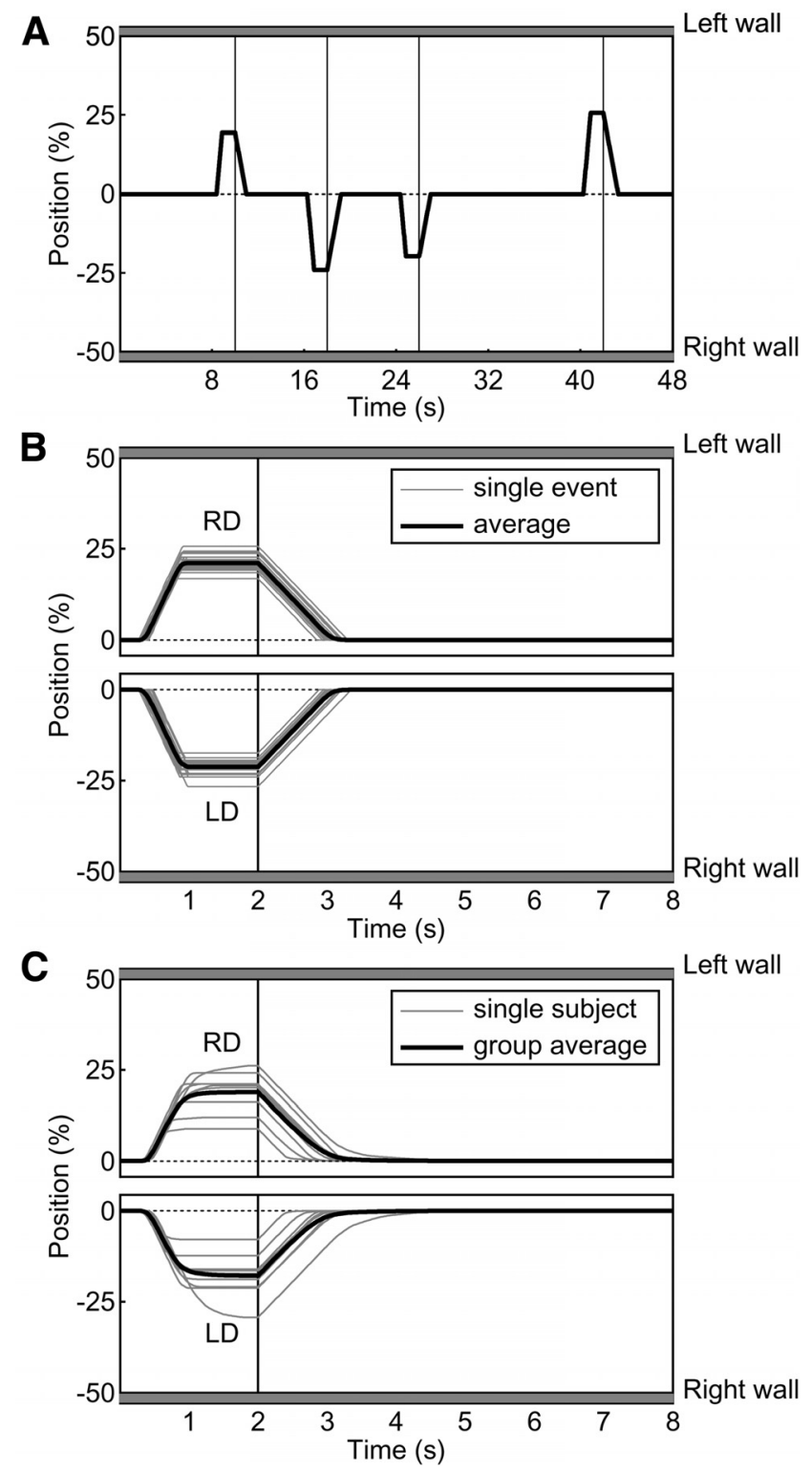

Figure 3. Egomotion trajectories during active dodges. $A$, A sample trajectory (including $\mathrm{W}$ $R D, L D, L D, W$, and RD events) from a representative subject. Each solid vertical line indicates the beginning of an automatic return to the hallway center $(0 \%)$. $\boldsymbol{B}$, Single and average trajectories of $32 \mathrm{LD}$ events (bottom) and $32 \mathrm{RD}$ events (top) from the same subject as in $A$. C, Single-subject and group average $(n=10)$ trajectories. See Table 1 for the maximum lateral displacement from the hallway center.

automatically return to the hallway center after $2 \mathrm{~s}$ in each event (Figs. 1, 2,3 ). Subjects viewed essentially the same stimuli with the same speed of egomotion in passive and active dodges. The only difference was that subjects briefly took control of the translational egomotion in active dodges (Fig. 2, thick black segment). Button presses were recorded at 60 $\mathrm{Hz}$ by a fiber optic response pad (Current Designs) placed under the right hand.

\section{Image acquisition}

Functional and structural images were acquired with an eight-channel head coil in a General Electric MR750 3 tesla scanner at the Center for Functional MRI at UCSD. In each session, echoplanar images (EPIs) were acquired in four functional scans [single-shot EPI; flip angle, $60^{\circ}$; echo time, $30.1 \mathrm{~ms}$; repetition time (TR), $1000 \mathrm{~ms}$; FOV, $224 \times 224 \mathrm{~mm}$; voxel size, $3.5 \times 3.5 \times 4.5 \mathrm{~mm}$; 19 axial slices; matrix, $64 \times 64$; 384 TRs per volume after discarding 8 dummy TRs]. Two field-map scans were 


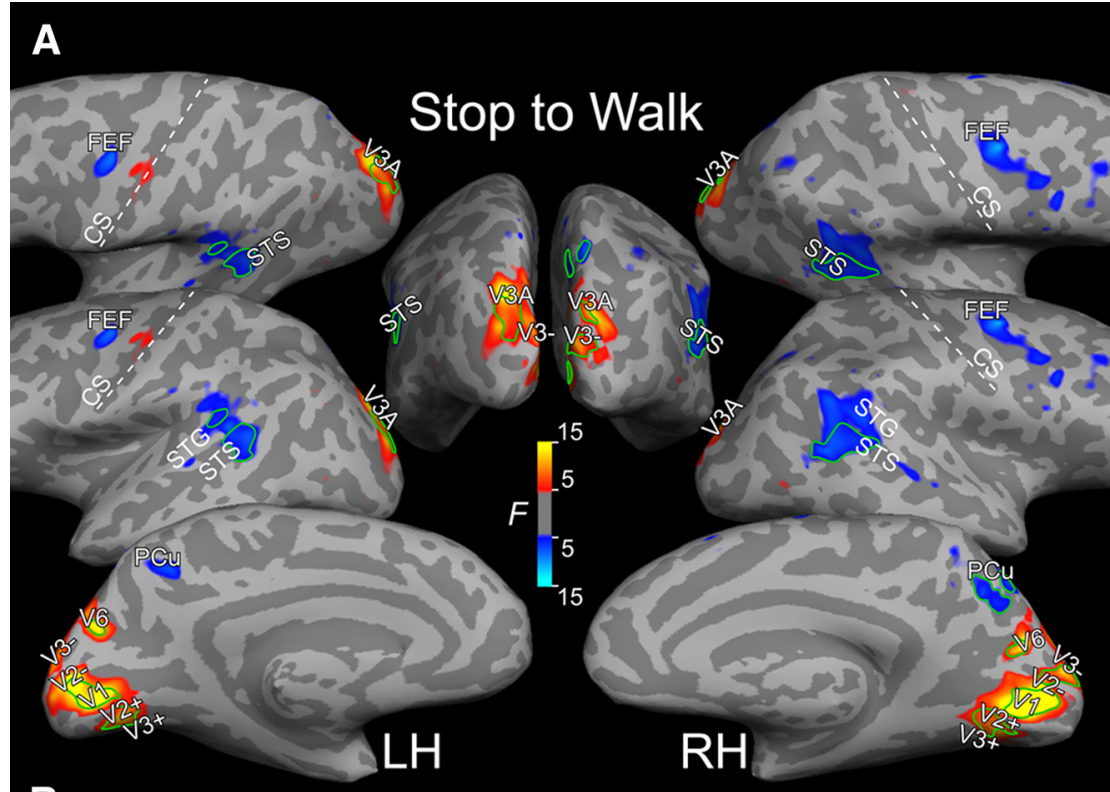

B
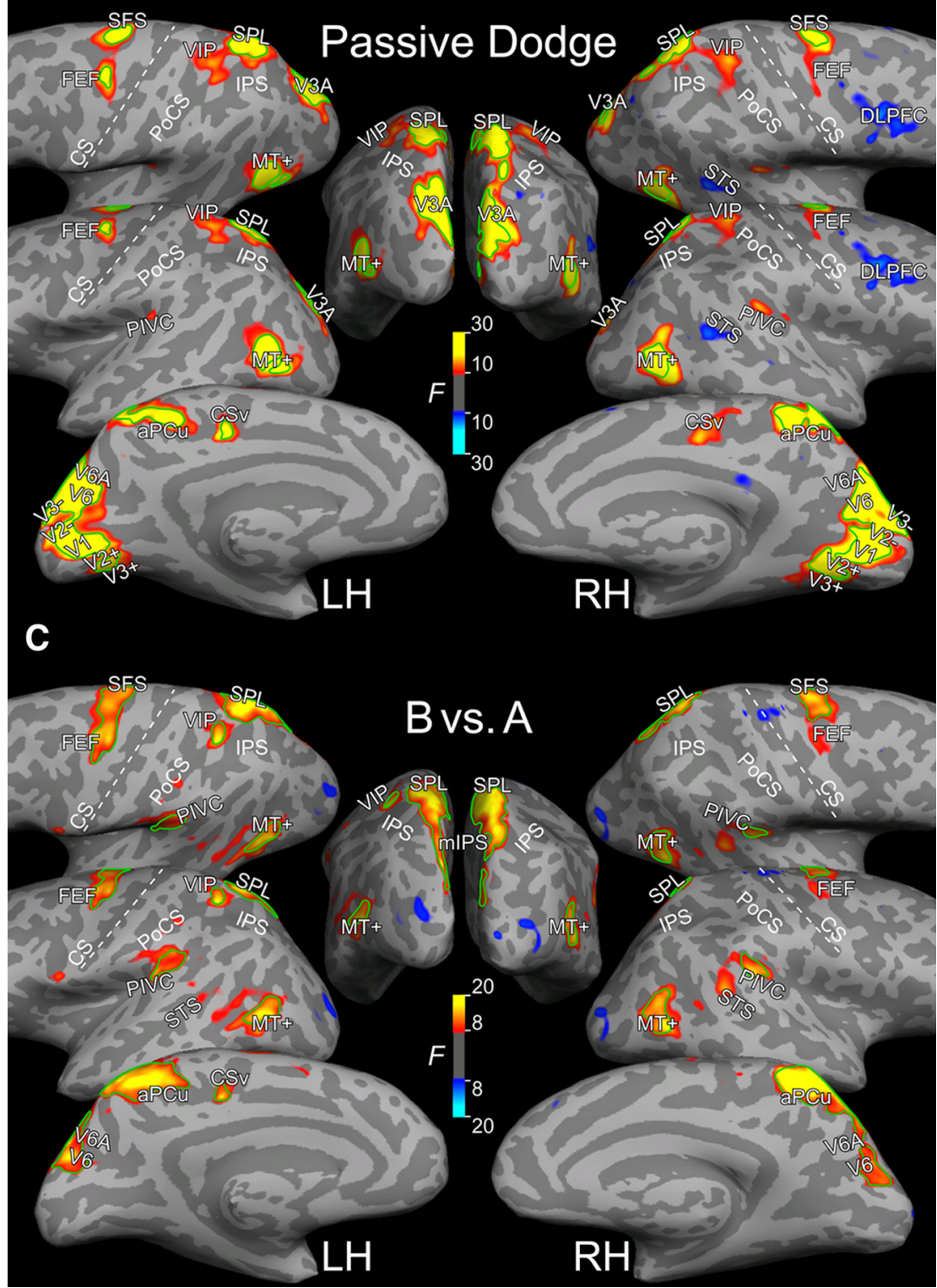

acquired with the same positions and dimensions as the functional scans. An alignment scan [fast spoiled gradient echo (FSPGR); FOV, $256 \times 256 \mathrm{~mm}$; voxel size, $1 \times 1 \times 1.3$ mm; 106 axial slices; matrix, $256 \times 256$ ] was acquired at the same volume center and orientation as the functional images for registration between scans. In a different session, two sets of high-resolution structural images (FSPGR images; FOV, $256 \times 256 \mathrm{~mm}$; voxel size, $1 \times 1 \times$ $1 \mathrm{~mm} ; 160-170$ axial slices; matrix, $256 \times 256$ ) were acquired and averaged for cortical surface reconstruction for each subject.

\section{Data analysis}

Image preprocessing. For each subject, geometric distortions in functional images were first corrected using two field-map scans (http://fmri.ucsd.edu/Howto/3T/fieldmap. $\mathrm{h} \mathrm{t} \mathrm{m} \mathrm{l}$ ). Two field map-corrected functional scans of the same experiment were concatenated (768 TRs total) and then motion corrected using the 3 dvolreg tool of the Analysis of Functional NeuroImages (AFNI) software package (Cox, 1996; http://afni.nimh.nih.gov). The FreeSurfer software package (Dale et al., 1999; Fischl et al., 1999a; http://surfer.nmr.mgh.harvard.edu) was used to reconstruct cortical surfaces from the averaged high-resolution structural images for each subject. Functional images were registered with individual cortical surfaces by manually refining the overlay between functional and structural images using a transformation matrix initially obtained by registering the alignment scan to the high-resolution structural images.

Functional data analysis. The blood oxygenation level-dependent (BOLD) signals (768 time points) of each voxel in functional images were analyzed using the general linear model implemented with the AFNI 3dDeconvolve tool (Ward, 2002). The following regressors were included in the model: (1) baseline trends consisting of constant, linear, and quadratic drifting; (2) motion parameters ( $6 \mathrm{df}$ ) obtained by AFNI 3dvolreg tool; and (3) a time series (stimulus pattern) defining the onset of each event (S2W, LD, and RD for Experiment 1; LD and RD for Experiment 2). In each time series, the period of each event onset ( 3 TRs) was set to 1 while the nonevent period (baseline) was set to 0 (Fig. 2). In Experiment 2, the onset of

\section{$\leftarrow$}

Figure 4. Group average statistical maps activated by the observation of passive dodges during egomotion. $A$, Events of S2W transition. $\boldsymbol{B}, \mathrm{LD}$ and RD events combined (LD + RD). $\boldsymbol{C}$, Linear contrast between $\boldsymbol{B}$ and $\boldsymbol{A}(\mathrm{LD}+\mathrm{RD}-\mathrm{S} 2 \mathrm{~W})$. LH, Left hemisphere; RH, right hemisphere; CS, central sulcus; PoCS, postcentral sulcus. Each map shows the group average of $F_{(1,713)}$, with activation (positive) rendered in dark red to bright yellow, and deactivation (negative) rendered in dark blue to bright cyan. The $F$ statistic values of each color bar correspond to a range of uncorrected $p$ values from $1.2 \times$ $10^{-4}$ to $2.6 \times 10^{-2}$ in $A, 6.0 \times 10^{-8}$ to $1.6 \times 10^{-3}$ in $B$, and $9.0 \times 10^{-6}$ to $4.8 \times 10^{-3}$ in $C$. Regions enclosed in green contours indicate that the average $F$ statistic values are significant across subjects $\left(t_{(9)}>2.26, p<0.05\right.$, cluster corrected). 
each LD or RD event overlapped with the subject's response, which could not be separated from the entire event due to the low temporal resolution of fMRI. The maximum time lag for estimating the hemodynamic response function was 8 TRs. The additions and subtractions of events ( $\mathrm{LD}+\mathrm{RD}$ and $\mathrm{LD}+\mathrm{RD}-\mathrm{S} 2 \mathrm{~W})$ were also computed using the option of general linear test in $3 \mathrm{dDeconvolve.} \mathrm{The} \mathrm{sign} \mathrm{of} \mathrm{activa-}$ tion (positive or negative BOLD signals) was determined by summing the area under each estimated hemodynamic response curve (Chevrier et al., 2007), and then multiplied by the $F$ statistic to generate a signed $F$ value for each voxel. A positive sign indicates an overall increase in BOLD signals, while a negative sign indicates that BOLD signals were negatively correlated with the event onset. The resulting statistical maps were rendered on inflated cortical surfaces of each subject using FreeSurfer.

Surface-based group average maps. Spherical-averaging methods were used to obtain surface-based group average maps of $F$ statistics (Fischl et al., 1999b; Hagler and Sereno, 2006; Hagler et al., 2007). Each individual surface was inflated into a sphere and then morphed into an optimal sulcal align-

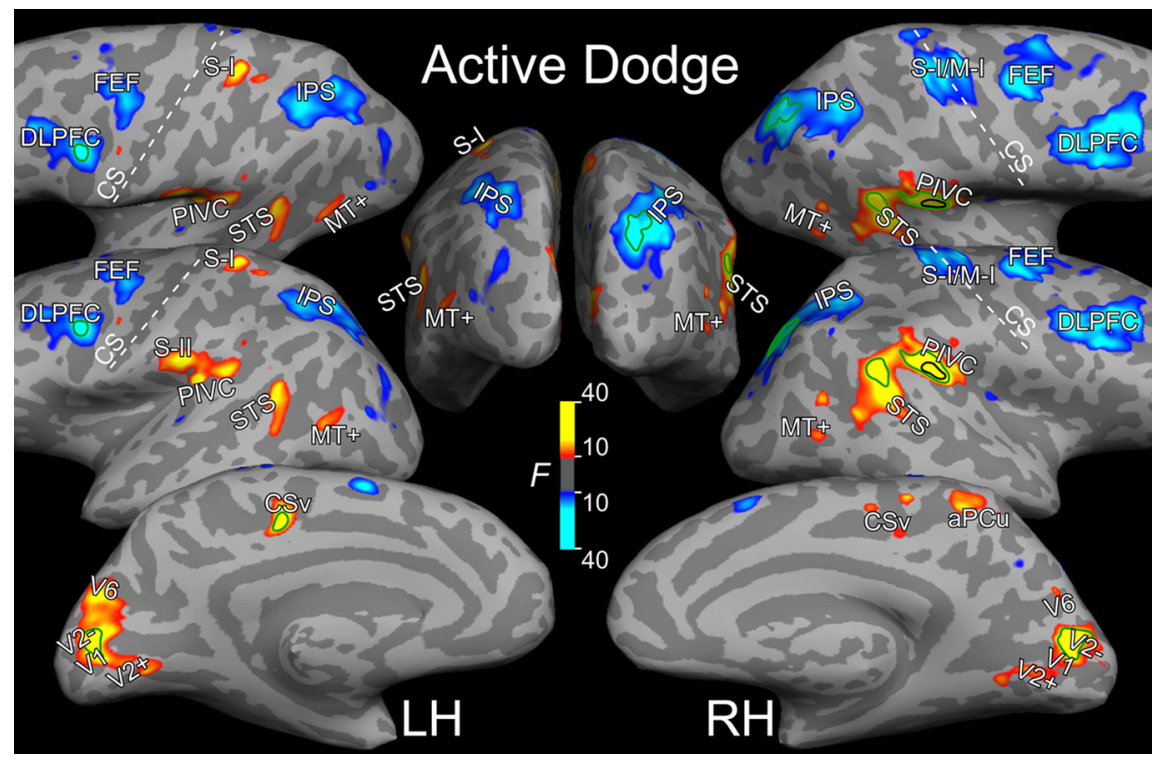

Figure 5. Group-average statistical maps activated by active dodges ( $L D$ and RD events combined) during egomotion. Statistical thresholds of $F_{(1,722)}$ correspond to a range of uncorrected $p$ values between $4.5 \times 10^{-10}$ and $1.6 \times 10^{-3}$. The black contour indicates the only area (right PIVC) with uncorrected $p$ values smaller than $4.5 \times 10^{-10}$. Regions enclosed in green contours indicate that the average $F$ statistic values are significant across subjects $\left(t_{(9)}>2.26, p<0.05\right.$, cluster corrected). 0 ther conventions follow Figure 4. S-I, primary somatosensory cortex; M-I, primary motor cortex; S-II, secondary somatosensory cortex. ment with an average sphere (Fischl et al.,

1999b). The morphed sphere was then used to sample and project individual surface-based $F$ statistics (signed) onto a common spherical coordinate system using the mri_surf2surf tool of FreeSurfer. An average $F$ value was obtained by averaging signed $F$ statistics across subjects $(n=10)$ on the common spherical coordinate system and then back-sampled onto the cortical surface of one representative subject (Figs. 4, 5). A high $F$ value in a surface-based region of interest (ROI) on the average sphere suggests that corresponding ROIs in individual subjects were highly similar in their activation (or deactivation) patterns and sulcal alignment. A two-tailed $t$ test was used to assess whether the average $F$ value is significant across subjects. Finally, surface-based cluster exclusion methods were used to correct for multiple comparisons of group $t$ statistics on the average surface (Hagler et al., 2006).

Identification and labeling of ROIs. ROIs in Figures 4 and 5 were identified and labeled by surface-based warping of average reference maps from our previous studies and then projecting them onto individual cortical surfaces in the current study (data not shown). Areas V6/V6A, anterior precuneus (aPCu), CSv, VIP, frontal eye field (FEF), and PIVC were identified by a wide-field motion-localizer experiment that contrasted structured motion with scrambled motion (Sereno and Huang, 2006). The middle temporal (MT) area was identified on retinotopic maps as a temporal region containing a complete map of the contralateral hemifield (Huang et al., 2012; Huang and Sereno, 2013). In the current study, middle temporal motion complex $(\mathrm{MT}+)$ was used to label a large ROI encompassing area MT and surrounding areas (Fig. 4B). Furthermore, areas V1/V2/V3, V3A, V6/V6A, aPCu, CSv, VIP, superior parietal lobule (SPL), FEF, superior frontal sulcus (SFS), and PIVC can also be identified and labeled based on reference retinotopic maps (Huang et al., 2012; Huang and Sereno, 2013). CSv was identified as a region with an emphasis on the lower visual field in the cingulate sulcus. aPCu was identified as a complete retinotopic map at the junction of the anterior precuneus and the ascending ramus of the posterior cingulate sulcus. VIP (parietal face area) was identified as a complete retinotopic map at the dorsal end of the postcentral sulcus. SPL (parietal body area) was identified as a region with an emphasis on the lower visual field located just posterior and medial to VIP. PIVC was identified as an isolated region located at the posterior end of the lateral sulcus (Brandt and Dieterich, 1999).
Table 1. Behavioral results in Experiment 2

\begin{tabular}{|c|c|c|c|c|c|c|}
\hline \multirow[b]{2}{*}{ Subject } & \multicolumn{3}{|c|}{ Reaction time (ms) } & \multicolumn{3}{|c|}{ Maximum lateral displacement (\%) } \\
\hline & LD & RD & LD and RD & LD & RD & LD and RD \\
\hline 1 & 419 & 391 & 405 & $21.8 \pm 3.5$ & $24.1 \pm 1.5$ & $23.0 \pm 2.9$ \\
\hline 2 & 492 & 476 & 484 & $29.4 \pm 8.5$ & $26.1 \pm 8.2$ & $27.7 \pm 8.5$ \\
\hline 3 & 483 & 457 & 470 & $17.3 \pm 2.5$ & $18.6 \pm 3.0$ & $18.0 \pm 2.8$ \\
\hline 4 & 361 & 359 & 360 & $21.2 \pm 2.0$ & $21.1 \pm 1.9$ & $21.1 \pm 1.9$ \\
\hline 5 & 444 & 478 & 460 & $17.9 \pm 2.2$ & $20.7 \pm 4.9$ & $19.3 \pm 4.0$ \\
\hline 6 & 357 & 377 & 367 & $12.4 \pm 2.8$ & $11.9 \pm 3.6$ & $12.2 \pm 3.3$ \\
\hline 7 & 407 & 406 & 407 & $16.1 \pm 2.1$ & $16.1 \pm 1.8$ & $16.1 \pm 2.0$ \\
\hline 8 & 442 & 411 & 426 & $7.9 \pm 1.6$ & $8.8 \pm 3.1$ & $8.3 \pm 2.5$ \\
\hline 9 & 428 & 431 & 430 & $17.3 \pm 3.7$ & $20.1 \pm 6.3$ & $18.7 \pm 5.3$ \\
\hline 10 & 402 & 404 & 403 & $18.8 \pm 3.8$ & $21.8 \pm 4.2$ & $20.3 \pm 4.2$ \\
\hline Average & $423 \pm 43$ & $419 \pm 39$ & $421 \pm 39$ & $18.0 \pm 5.4$ & $18.9 \pm 5.1$ & $18.5 \pm 5.2$ \\
\hline $\mathrm{CV}$ & 0.1 & 0.092 & 0.093 & 0.301 & 0.267 & 0.279 \\
\hline
\end{tabular}

Maximum lateral displacement (percentage of the width of the hallway) was measured from the hallway center.

\section{Results}

Experiment 1

Figure 4 shows the surface-based group average of statistical maps $(n=10)$ activated by passive observation of forward and translational egomotion.

\section{Forward egomotion}

The transition from stopping to walking activated the upper and lower visual field representations of areas V1/V2/V3, area V6 (Pitzalis et al., 2006), and area V3A (Tootell et al., 1997) in both hemispheres (Fig. 4A). S2W events also induced deactivation in the FEF, $\mathrm{PCu}$, and a region extending from the superior temporal sulcus (STS) to the superior temporal gyrus (STG) bilaterally (see Discussion).

\section{Passive dodge}

Observation of passive dodges (LD and RD events combined) activated both early and higher-level visual areas bilaterally (Fig. $4 B$ ), including V1/V2/V3 (upper and lower visual field representations), V6/V6A, V3A, posterior intraparietal sulcus (IPS), VIP and SPL (Sereno and Huang, 2006; Huang et al., 2012), aPCu 


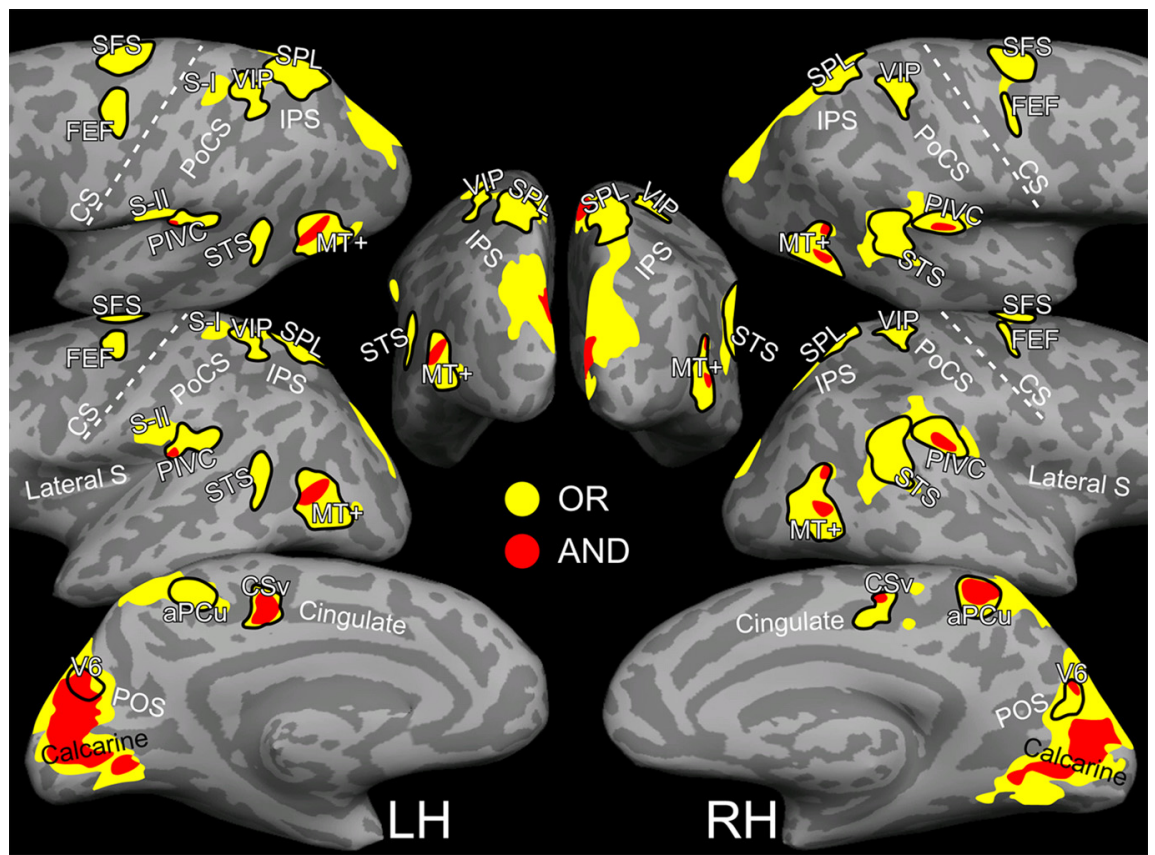

Figure 6. Conjunction map and ROI contours. A fixed statistical threshold ( $p=1.6 \times 10^{-3}$, uncorrected) was set to determine regions activated in either passive or active dodges (OR; yellow), and regions activated in both passive and active dodges (AND; red). POS, Parieto-occipital sulcus.

(Filimon et al., 2009), CSv (Wall and Smith, 2008; Furlan et al., 2014), MT+, PIVC, and FEF and SFS (Sunaert et al., 1999) in the frontal cortex. Observation of LD-only or RD-only events activated essentially the same set of visual areas in both hemispheres, with minor variations in their exact extent and statistical significance (data not shown). Deactivation was shown in STS and dorsolateral prefrontal cortex (DLPFC) in the right hemisphere.

\section{Contrast between events}

A linear contrast between events, $(\mathrm{LD}+\mathrm{RD})-\mathrm{S} 2 \mathrm{~W}$, was performed to subtract the component of forward egomotion (S2W) from passive dodges $(\mathrm{LD}+\mathrm{RD})$. As shown on the resulting statistical map (Fig. 4C), this contrast eliminated activation in early visual areas $\mathrm{V} 1 / \mathrm{V} 2 / \mathrm{V} 3$ and $\mathrm{V} 3 \mathrm{~A}$ while retaining activation in higher-level visual areas, including $\mathrm{MT}+$, STS, PIVC, V6/V6A, aPCu, CSv (only in the left hemisphere), medial IPS (mIPS), SPL, VIP (only in the left hemisphere), FEF, and SFS. This contrast also showed relatively stronger activation in STS and PIVC in passive dodges (comprising forward and translational egomotion) than in forward egomotion (see Discussion).

\section{Experiment 2}

\section{Behavioral results}

In Experiment 2, subjects responded to each swinging door by holding down a button on a two-button response pad to dodge the door in the opposite direction (i.e., the left button for the right door, and vice versa). Reaction time (RT) was measured from the beginning of each sustained button press (the onset of a dodge). The variation of $\mathrm{RT}$ was small across subjects [coefficient of variance $(\mathrm{CV})=0.093$; $\mathrm{LD}$ and $\mathrm{RD}$ events combined], and there was no significant difference $\left(t_{(9)}=-0.63 ; p=0.54\right.$, uncorrected) between the RTs in LD and $\mathrm{RD}$ events (Table 1). However, subjects showed a large variation $(\mathrm{CV}=0.279)$ in their subjective judgment in reaching a margin of safety (the maximum lateral displacement from the hallway center), ranging from $8.3 \%$ to $27.7 \%$ of the width of the virtual hallway (LD and RD events combined; Table 1).
Group-average statistical maps

Group-average statistical maps $(n=10)$ driven by active dodges (LD and RD events combined) are rendered in Figure 5 , which shows significant activation in areas V1/V2, V6 (predominantly in the left hemisphere), CSv (only in the left hemisphere), aPCu (only in the right hemisphere), left primary and secondary somatosensory cortices (contralateral finger representations), part of $\mathrm{MT}+$, STS, and PIVC. Active dodges also resulted in deactivation in the right primary somatosensory and motor cortex; and in bilateral IPS, FEF, and DLPFC. The strongest activation was located in a large region encompassing STS, posterior STG, and PIVC in the right hemisphere. Among them, PIVC showed the highest level of statistical significance (group average: $F_{(1,722)}>40, p<4.5 \times 10^{-10}$, uncorrected; $t_{(9)}>3.1, p<0.013$, corrected; Fig. 5, black contour).

\section{Conjunction and contrast analyses}

A surface-based conjunction analysis was performed to determine whether a region was activated in either or both experiments. Group-average activation maps of passive and active dodges were rendered on the same cortical surfaces of a representative subject (Figs. $4 B, 5$ ), with a signed $F$ value from each map assigned to each vertex on the surface. Surface-based "AND" and "OR" Boolean operations were used to determine whether either or both $F$ values (positive only) at each vertex were higher than a fixed statistical threshold ( $p=1.6 \times 10^{-3}$, uncorrected). Regions commonly activated by passive and active dodges include part of bilateral V1/V2, V6, MT+, CSv, and PIVC; and the right aPCu (Fig. 6, red regions).

To contrast BOLD signals between passive and active dodges, 10 surface-based ROIs in each hemisphere were outlined from the group-average conjunction map (Fig. 6) and then were backsampled onto individual cortical surfaces to identify ROIs in each subject. Table 2 shows the group average of Talairach coordinates and an estimated $p$ value for each ROI. Voxels associated with each ROI were selected from each functional dataset. Epochs $(8 \mathrm{~s}$ each) time-locked to the beginning of the same event were extracted from the BOLD signals of each voxel and then averaged across voxels in each ROI of each subject. For each ROI, the maximum of average BOLD signal change following the event onset was measured and averaged across subjects in each experiment. On average, PIVC, STS, SFS, and CSv showed a larger percentage signal change following active dodges in both hemispheres (Fig. 7). Among them, only PIVC showed a significant difference between active and passive dodges $(p<0.05$, paired $t$ test, Bonferroni corrected).

\section{Temporal dynamics in PIVC}

To investigate the temporal dynamics in PIVC in response to random events of active dodges, triplets of $8 \mathrm{~s}$ epochs (24 TRs; $24 \mathrm{~s}$ ) were extracted from the time series of each voxel and averaged. The resulting triplets were averaged across voxels within each ROI of PIVC and then across subjects (Fig. 8). There were eight possible triplet combinations, DDD, DDW, DWD, DWW, 
Table 2. Group average Talairach coordinates and $p$ value in each ROI

\begin{tabular}{|c|c|c|c|c|c|c|}
\hline \multirow[b]{2}{*}{ ROI } & \multicolumn{3}{|l|}{ Left hemisphere } & \multicolumn{3}{|l|}{ Right hemisphere } \\
\hline & $(x, y, z)$ & Passive $p$ value & Active $p$ value & $(x, y, z)$ & Passive $p$ value & Active $p$ value \\
\hline PIVC & $(-49.1,-37.5,23.8)$ & $3.3 \times 10^{-2}$ & $1.2 \times 10^{-6}$ & $(54.9,-35.6,26.9)$ & $3.4 \times 10^{-2}$ & $1.4 \times 10^{-8}$ \\
\hline STS & $(-47.5,-53.3,13.6)$ & $1.2 \times 10^{-2}$ & $2.8 \times 10^{-4}$ & $(55.7,-44.4,22.5)$ & $1.4 \times 10^{-1}$ & $1.4 \times 10^{-5}$ \\
\hline MT+ & $(-42.3,-71.6,5.9)$ & $1.0 \times 10^{-6}$ & $9.9 \times 10^{-3}$ & $(43.8,-67.8,6.3)$ & $1.3 \times 10^{-6}$ & $1.3 \times 10^{-2}$ \\
\hline SFS & $(-19.3,-9.5,60.2)$ & $7.8 \times 10^{-6}$ & $9.5 \times 10^{-2}$ & $(24.3,-6.6,56.4)$ & $4.8 \times 10^{-6}$ & $1.1 \times 10^{-2}$ \\
\hline FEF & $(-34.8,-7.8,49.8)$ & $2.7 \times 10^{-4}$ & $3.6 \times 10^{-3}$ & $(40.4,-8.6,54.5)$ & $1.2 \times 10^{-4}$ & $1.5 \times 10^{-1}$ \\
\hline VIP & $(-29.6,-41.5,58.8)$ & $4.8 \times 10^{-4}$ & $4.6 \times 10^{-2}$ & $(31.1,-40.2,53.7)$ & $1.2 \times 10^{-4}$ & $1.8 \times 10^{-1}$ \\
\hline SPL & $(-17.8,-57.2,63.8)$ & $3.8 \times 10^{-6}$ & $3.4 \times 10^{-2}$ & $(19.5,-57.6,65.2)$ & $9.8 \times 10^{-7}$ & $9.4 \times 10^{-2}$ \\
\hline V6 & $(-13.0,-80.5,34.0)$ & $1.5 \times 10^{-9}$ & $1.9 \times 10^{-3}$ & $(16.0,-79.4,32.0)$ & $4.4 \times 10^{-11}$ & $4.7 \times 10^{-2}$ \\
\hline $\mathrm{CSV}$ & $(-10.2,-20.5,43.1)$ & $3.0 \times 10^{-4}$ & $1.3 \times 10^{-5}$ & $(11.8,-18.8,46.5)$ & $2.5 \times 10^{-5}$ & $3.5 \times 10^{-3}$ \\
\hline $\mathrm{aPCu}$ & $(-12.2,-46.2,56.0)$ & $1.8 \times 10^{-5}$ & $2.7 \times 10^{-2}$ & $(11.9,-48.3,58.5)$ & $1.1 \times 10^{-6}$ & $3.8 \times 10^{-3}$ \\
\hline
\end{tabular}

Each $p$ value (Bonferroni corrected) was estimated by group average $(n=10)$ of the median $F$ value in each ROI of each subject. Bold type indicates the smaller $p$ value between passive and active dodges for the same ROI.

\section{Left Hemisphere}

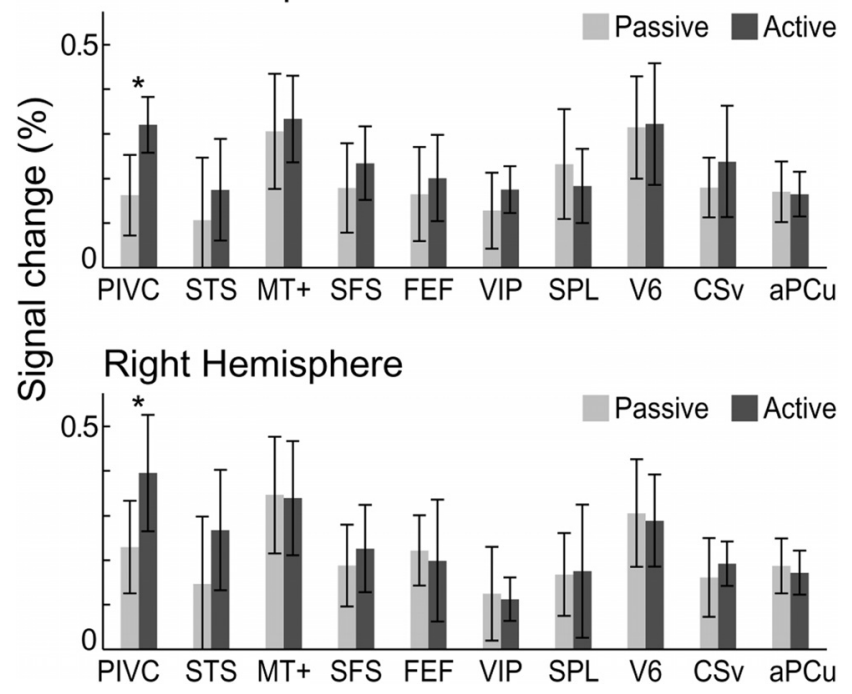

Figure 7. Group average of the maximum BOLD signal change in surface-based ROls. Error bars represent $\pm 1 S D(n=10)$. The asterisk indicates a significant difference between passive and active dodges ( $p<0.05$, paired $t$ test, Bonferroni corrected).

WDD, WDW, WWD, and WWW, where D represents a door-dodging event (LD or RD) and W represents straight walking with doors closed. The counts of triplets differed because (1) the original random event sequences did not balance the probabilities of different triplets, and (2) there were overlaps between triplets (e.g., the last two epochs of DWW overlapped with the first two epochs of WWD). On average, the right PIVC showed a slightly larger percentage signal change, as evident in triplet DDD. The average time course of the WDW triplet showed a complete canonical hemodynamic response curve comprising an initial dip, a maximum, and a postevent undershoot (Sotero and Trujillo-Barreto, 2007). The initial dip immediately after the event onset was evident in each W-to-D transition in triplets DWD, WDD, WDW, and WWD; while the postevent undershoot was evident in each D-to-W transition in triplets DDW, DWD, DWW, and WDW. The postevent undershoot was more negative than the initial dip in triplets DWD and WDW, which contained unaffected W-to-D and D-to-W transitions. In triplets DDD, DDW, and WDD, no postevent undershoot was observed between two consecutive $\mathrm{D}$ epochs, and the activation peaked at approximately the same time within each epoch. In triplets DWW, WWD, and WWW, a relative dip was observed in the second and third $\mathrm{W}$ epochs, even though they were not preceded by $\mathrm{D}$ events.

\section{Discussion}

Previous studies on egomotion have primarily focused on the perceptual processing of visual motion. Several higher-level motion areas, including MST, PIVC, VIP, CSv, and V6, have been revealed by passive viewing of optic flow stimuli in human neuroimaging studies. Here we compared activation maps of (1) passive observation and (2) active control of translational egomotion in response to randomly swinging doors during simulated walking in a VR environment. In both experiments, subjects viewed essentially the same stimuli but briefly took control in active dodges, which resulted in a different recruitment of higherlevel motion areas, as discussed below.

\section{Passive observation}

Passive observation of S2W events activated early visual areas (V1/V2/V3) and motion-sensitive areas V3A and V6 (Fig. 4A). Other motion areas, including MT+, VIP, PIVC, and CSv, did not respond as strongly to the VR scenes that induced a sense of slow forward egomotion. This is likely because the virtual hallway was rendered with smooth and low-contrast textures. The relative response between V6 and MT + is consistent with a study showing that V6 responded more strongly to coherent flow-field stimuli than did MST (Pitzalis et al., 2010). S2W events also resulted in deactivation in the precuneus, FEF, and a region encompassing STS, STG, and PIVC (Fig. 4A). Precuneus and STG have been considered part of the vestibular cortical network (Dieterich, 2007). Deactivation in these areas is likely due to the absence of vestibular inputs during simulated egomotion, which is consistent with a mechanism of reciprocal inhibitory interaction between the visual and vestibular systems (Brandt et al., 1998; Dieterich, 2007).

Areas V1, V2, V3, V6, V6A, aPCu, CSv, V3A, VIP, SPL, MT+, PIVC, FEF, and SFS (Fig. 4B) were activated by passive observation of dodges, each consisting of forward egomotion, object motion (a swinging door), and translational egomotion. Subtracting the component of forward egomotion (S2W events) from the activation maps eliminates the early visual areas (V1/ $\mathrm{V} 2 / \mathrm{V} 3$ and V3A) while retaining the higher-level areas (Fig. 4C), which can be approximately divided into three dorsal motion streams distributed in the temporal, parietal, and cingulate cortex (Huang and Sereno, 2013). The first motion stream starts at $\mathrm{MT}+$, extends into STS, and reaches PIVC in the posterior lateral sulcus. Activation in $\mathrm{MT}+$ can be accounted for by a combination of object motion (swinging doors) and whole-field translational egomotion. Areas STS and PIVC showed deactivation in S2W events (Fig. 4A) and weak activation in passive dodges (Fig. $4 B$ ). The contrast between these two events resulted in relatively "positive" activation in STS and PIVC (Fig. 4C). 


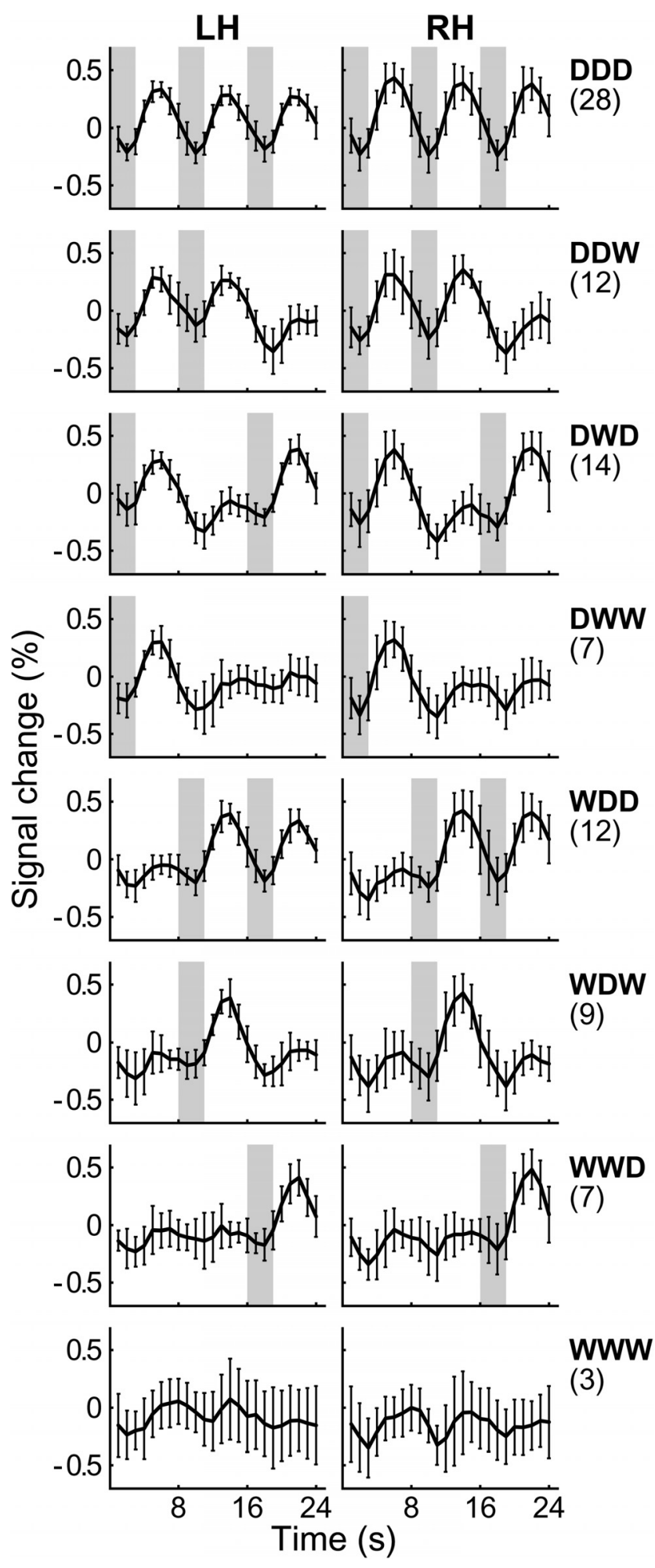

Figure 8. Group average of temporal dynamics in PIVC during active dodges. The count of each triplet combination is indicated in the parentheses. Each light gray bar represents the duration ( $\sim 3 s$ ) of a door-dodging event ( $L D$ or RD). The percentage signal change is relative to the mean of fMRI time series in each voxel. Error bars represent \pm 1 SD $(n=10)$.

The second motion stream starts at the posterior MIPS and reaches the superior postcentral sulcus. Areas mIPS, VIP, and SPL on this stream play important roles in spatial attention in multiple reference frames (eye centered, head centered, and body centered). Specifically, mIPS overlaps with multiple retinotopic areas considered to be the human homolog of macaque lateral intraparietal area (Sereno et al., 2001; Hagler et al., 2007; Konen and Kastner, 2008). Furthermore, mIPS responds to radial optic flow patterns (Konen and Kastner, 2008) and is important in detecting heading directions during simulated or imagined egomotion (Billington et al., 2010; Huang and Sereno, 2013). Areas VIP (parietal face area) and SPL (parietal body area) contain multisensory maps of peripersonal space and respond to looming objects (Sereno and Huang, 2006; Huang et al., 2012). Passive dodges more strongly activated SPL than VIP (Figs. 4, 7), suggesting that the swinging door that occupied the whole hemifield may be more relevant to the entire body (SPL) than just the head (VIP). To reduce motion artifacts (due to head movements), we programmed the door to swing at a moderate speed that only prompted the direction of translational egomotion but did not induce a strong sense of imminent collision. This may account for the weak activation in VIP and absent activation in the anterior insula (Billington et al., 2011).

The third motion stream starts at the parieto-occipital sulcus (V6/V6A), extends into aPCu, and reaches CSv. Both V6 and CSv are sensitive to wide-field egomotion-compatible stimuli, but only CSv is activated by galvanic vestibular stimulation (Cardin and Smith, 2010; Pitzalis et al., 2010, 2013a; Smith et al., 2012). Furthermore, CSv was activated in passive dodges (translational and forward egomotion) but not in S2W events (forward egomotion). This is consistent with a recent study (Furlan et al., 2014) showing that CSv responded strongly to changing heading direction. V6A is located dorsal to V6, and contains representations of the lower visual field and the periphery (Pitzalis et al., 2013b). $\mathrm{aPCu}$ contains a complete retinotopic map; responds to egomotion-compatible stimuli; and plays important roles in proprioception, imagined egomotion, and vestibular processing (Filimon et al., 2009; Cardin and Smith, 2010; Huang et al., 2012; Huang and Sereno, 2013). In addition to the three motion streams, activation was found in frontal areas FEF and SFS, which are known to be motion sensitive (Sunaert et al., 1999).

\section{Active control}

In Experiment 2, the variation in reaction time was small across subjects, suggesting that they were equally attentive and responsive. However, the variation in the lateral displacement away from the swinging door was larger between than within subjects (Table 1). This suggests that most subjects made consistent judgments in reaching a personal margin of safety, but there was a large individual difference as to where that margin of safety was (Fig. 3C).

Among the dorsal motion streams activated by passive dodges, the temporal-vestibular stream ending at PIVC was most strongly and consistently activated by active dodges (Fig. 5). Activation in the other two streams was weak or absent. VIP on the parietal stream is known to respond to looming stimuli and changing heading directions (Huang et al., 2012; Furlan et al., 2014). In the current study, VIP was relatively inactive because the swinging door was not perceived as an imminent collision. Once the door swung open and a dodge was initiated, PIVC then actively engaged in translational egomotion and determined when to stop the dodge. On the medial motion stream, areas V6, $\mathrm{CSv}$, and aPCu showed asymmetric activation between hemispheres, which needs further investigation.

Across subjects, the right PIVC showed a larger area (at a fixed statistical threshold), a higher level of average statistical significance, and a larger average BOLD signal change than the left PIVC (Figs. 5, 7,8 ; Table 2). This asymmetry is consistent with a right hemispheric 
dominance of the vestibular cortex in right-handed subjects, as suggested by previous neuroimaging studies using visual, optokinetic, and vestibular stimuli (Dieterich et al., 1998, 2003).

When making comparisons across events, PIVC showed deactivation in forward egomotion (S2W events), weak activation in passive dodges, and strong activation in active dodges. While V3A, MT+, SPL, SFS, V6/V6A, aPCu, and CSv were strongly activated by passive dodges (consisting of forward and translational egomotion), activation in PIVC was only minimal (Fig. $4 B)$. These results are consistent with a monkey physiology study (Chen et al., 2010) showing the absence of optic flow responses in PIVC. The role of PIVC in visual-vestibular integration remains controversial. In the present study, PIVC did not receive any vestibular stimulation as subjects remained motionless during active dodges (see natural head movements in Petit and Beauchamp, 2003). Subjects actively controlled their lateral positions with sustained button presses in a wide-field VR environment, which resulted in real-time visual feedback similar to that generated by actual dodges involving natural head and body movements. The strong activation in the right PIVC suggests that it plays an active role in visual guidance of translational egomotion rather than merely passive processing of optic flow. Finally, analysis of fMRI time series showed that PIVC promptly responded to repeating events with an interevent interval as short as $8 \mathrm{~s}$ (Fig. 8).

\section{Future directions}

In the current study, we demonstrated the use of wide-field VR to simulate near-realistic egomotion and object motion in fMRI experiments. This VR environment allows subjects to either passively view preprogrammed scenes or actively dodge obstacles. We also demonstrated a novel event-related design for studying temporal brain dynamics of active responses to sudden perturbation (e.g., moving obstacles) during an ongoing task (e.g., walking or driving) using interactive VR. Future fMRI studies on obstacle avoidance during simulated egomotion may include single or compound events selected from the following: (1) forward, translational, or rotational egomotion; (2) static or moving objects in eye-centered, head-centered, or body-centered reference frames; and (3) passive observation, active control (with buttons or joysticks), or overt limb and head movements (Petit and Beauchamp, 2003).

\section{Conclusion}

The neural substrates of egomotion have been revealed by passive viewing of optic flow patterns in previous human neuroimaging studies. We demonstrated that active control of translational egomotion could result in a different recruitment of neural resources even though the visual stimuli were identical to those in the passive observation experiment. Observation of passive dodges activated several higher-level visual areas distributed across three dorsal motion streams. Active dodges most strongly activated the right PIVC located at the end of the temporal-vestibular stream, suggesting that it plays an active role in sensing and guiding translational egomotion.

\section{References}

Billington J, Field DT, Wilkie RM, Wann JP (2010) An fMRI study of parietal cortex involvement in the visual guidance of locomotion. J Exp Psychol Hum Percept Perform 36:1495-1507. CrossRef Medline

Billington J, Wilkie RM, Field DT, Wann JP (2011) Neural processing of imminent collision in humans. Proc Biol Sci 278:1476-1481. CrossRef Medline

Billington J, Wilkie RM, Wann JP (2013) Obstacle avoidance and smooth trajectory control: neural areas highlighted during improved locomotor performance. Front Behav Neurosci 7:9. CrossRef Medline

Brandt T, Dieterich M (1999) The vestibular cortex. Its locations, functions, and disorders. Ann N Y Acad Sci 871:293-312. CrossRef Medline

Brandt T, Bartenstein P, Janek A, Dieterich M (1998) Reciprocal inhibitory visual-vestibular interaction. Visual motion stimulation deactivates the parieto-insular vestibular cortex. Brain 121:1749-1758. CrossRef Medline

Bremmer F (2011) Multisensory space: from eye-movements to selfmotion. J Physiol 589:815-823. CrossRef Medline

Bremmer F, Schlack A, Shah NJ, Zafiris O, Kubischik M, Hoffmann K, Zilles K, Fink GR (2001) Polymodal motion processing in posterior parietal and premotor cortex: a human fMRI study strongly implies equivalencies between humans and monkeys. Neuron 29:287-296. CrossRef Medline

Calabro FJ, Vaina LM (2012) Interaction of cortical networks mediating object motion detection by moving observers. Exp Brain Res 221:177189. CrossRef Medline

Cardin V, Smith AT (2010) Sensitivity of human visual and vestibular cortical regions to egomotion-compatible visual stimulation. Cereb Cortex 20:1964-1973. CrossRef Medline

Catena RD, van Donkelaar P, Halterman CI, Chou LS (2009) Spatial orientation of attention and obstacle avoidance following concussion. Exp Brain Res 194:67-77. CrossRef Medline

Chen A, DeAngelis GC, Angelaki DE (2010) Macaque parieto-insular vestibular cortex: responses to self-motion and optic flow. J Neurosci 30: 3022-3042. CrossRef Medline

Chevrier AD, Noseworthy MD, Schachar R (2007) Dissociation of response inhibition and performance monitoring in the stop signal task using event-related fMRI. Hum Brain Mapp 28:1347-1358. CrossRef Medline

Cox RW (1996) AFNI: software for analysis and visualization of functional magnetic resonance neuroimages. Comput Biomed Res 29:162-173. CrossRef Medline

Dale AM, Fischl B, Sereno MI (1999) Cortical surface-based analysis. I. Segmentation and surface reconstruction. Neuroimage 9:179-194. CrossRef Medline

Dieterich M (2007) Functional brain imaging: a window into the visuovestibular systems. Curr Opin Neurol 20:12-18. CrossRef Medline

Dieterich M, Bucher SF, Seelos KC, Brandt T (1998) Horizontal or vertical optokinetic stimulation activates visual motion-sensitive, ocular motor and vestibular cortex areas with right hemispheric dominance. An fMRI study. Brain 121:1479-1495. CrossRef Medline

Dieterich M, Bense S, Lutz S, Drzezga A, Stephan T, Bartenstein P, Brandt T (2003) Dominance for vestibular cortical function in the non-dominant hemisphere. Cereb Cortex 13:994-1007. CrossRef Medline

Duffy CJ (1998) MST neurons respond to optic flow and translational movement. J Neurophysiol 80:1816-1827. Medline

Duhamel JR, Colby CL, Goldberg ME (1998) Ventral intraparietal area of the macaque: congruent visual and somatic response properties. J Neurophysiol 79:126-136. Medline

Field DT, Wilkie RM, Wann JP (2007) Neural systems in the visual control of steering. J Neurosci 27:8002-8010. CrossRef Medline

Filimon F, Nelson JD, Huang RS, Sereno MI (2009) Multiple parietal reach regions in humans: cortical representations for visual and proprioceptive feedback during on-line reaching. J Neurosci 29:2961-2971. CrossRef Medline

Fischl B, Sereno MI, Dale AM (1999a) Cortical surface-based analysis. II: Inflation, flattening, and a surface-based coordinate system. Neuroimage 9:195-207. CrossRef Medline

Fischl B, Sereno MI, Tootell RB, Dale AM (1999b) High-resolution intersubject averaging and a coordinate system for the cortical surface. Hum Brain Mapp 8:272-284. CrossRef Medline

Furlan M, Wann JP, Smith AT (2014) A representation of changing heading direction in human cortical areas pVIP and CSv. Cereb Cortex 24:28482858. CrossRef Medline

Graziano MS, Cooke DF (2006) Parieto-frontal interactions, personal space, and defensive behavior. Neuropsychologia 44:2621-2635. CrossRef Medline

Hagler DJ Jr, Sereno MI (2006) Spatial maps in frontal and prefrontal cortex. Neuroimage 29:567-577. CrossRef Medline

Hagler DJ Jr, Saygin AP, Sereno MI (2006) Smoothing and cluster thresholding for cortical surface-based group analysis of fMRI data. Neuroimage 33:1093-1103. CrossRef Medline

Hagler DJ Jr, Riecke L, Sereno MI (2007) Parietal and superior frontal visu- 
ospatial maps activated by pointing and saccades. Neuroimage 35:15621577. CrossRef Medline

Hartley T, Maguire EA, Spiers HJ, Burgess N (2003) The well-worn route and the path less traveled: distinct neural bases of route following and wayfinding in humans. Neuron 37:877-888. CrossRef Medline

Huang RS, Sereno MI (2013) Bottom-up retinotopic organization supports top-down mental imagery. Open Neuroimag J 7:58-67. CrossRef Medline

Huang RS, Chen CF, Tran AT, Holstein KL, Sereno MI (2012) Mapping multisensory parietal face and body areas in humans. Proc Natl Acad Sci U S A 109:18114-18119. CrossRef Medline

Konen CS, Kastner S (2008) Representation of eye movements and stimulus motion in topographically organized areas of human posterior parietal cortex. J Neurosci 28:8361-8375. CrossRef Medline

Marigold DS (2008) Role of peripheral visual cues in online visual guidance of locomotion. Exerc Sport Sci Rev 36:145-151. CrossRef Medline

Pearson K, Gramlich R (2010) Updating neural representations of objects during walking. Ann N Y Acad Sci 1198:1-9. CrossRef Medline

Petit L, Beauchamp MS (2003) Neural basis of visually guided head movements studied with fMRI. J Neurophysiol 89:2516-2527. CrossRef Medline

Pitzalis S, Galletti C, Huang RS, Patria F, Committeri G, Galati G, Fattori P, Sereno MI (2006) Wide-field retinotopy defines human cortical visual area V6. J Neurosci 26:7962-7973. CrossRef Medline

Pitzalis S, Sereno MI, Committeri G, Fattori P, Galati G, Patria F, Galletti C (2010) Human V6: the medial motion area. Cereb Cortex 20:411-424. CrossRef Medline

Pitzalis S, Sdoia S, Bultrini A, Committeri G, Di Russo F, Fattori P, Galletti C,
Galati G (2013a) Selectivity to translational egomotion in human brain motion areas. PLoS One 8:e60241. CrossRef Medline

Pitzalis S, Sereno MI, Committeri G, Fattori P, Galati G, Tosoni A, Galletti C (2013b) The human homologue of macaque area V6A. Neuroimage 82: 517-530. CrossRef Medline

Sereno MI, Huang RS (2006) A human parietal face area contains aligned head-centered visual and tactile maps. Nat Neurosci 9:1337-1343. CrossRef Medline

Sereno MI, Pitzalis S, Martinez A (2001) Mapping of contralateral space in retinotopic coordinates by a parietal cortical area in humans. Science 294:1350-1354. CrossRef Medline

Smith AT, Wall MB, Thilo KV (2012) Vestibular inputs to human motionsensitive visual cortex. Cereb Cortex 22:1068-1077. CrossRef Medline

Sotero RC, Trujillo-Barreto NJ (2007) Modelling the role of excitatory and inhibitory neuronal activity in the generation of the BOLD signal. Neuroimage 35:149-165. CrossRef Medline

Sunaert S, Van Hecke P, Marchal G, Orban GA (1999) Motion-responsive regions of the human brain. Exp Brain Res 127:355-370. CrossRef Medline

Tootell RB, Mendola JD, Hadjikhani NK, Ledden PJ, Liu AK, Reppas JB, Sereno MI, Dale AM (1997) Functional analysis of V3A and related areas in human visual cortex. J Neurosci 17:7060-7078. Medline

Wall MB, Smith AT (2008) The representation of egomotion in the human brain. Curr Biol 18:191-194. CrossRef Medline

Ward BD (2002) Deconvolution analysis of fMRI time series data. AFNI $3 \mathrm{dDeconvolve}$ documentation. Milwaukee, WI: Medical College of Wisconsin. 